This is the final peer-reviewed accepted manuscript of:

[F. Grepioni,* S. d'Agostino,* D. Braga, A. Bertocco,a L. Catalano and B. Ventura* "Fluorescent crystals and co-crystals of 1,8-naphthalimide derivatives: synthesis, structure determination and photophysical characterization", Journal of Material Chemistry C, 2015, 3, 9425--9434]

The final published version is available online at:

[https://doi.org/10.1039/C5TC01518A]

Rights / License:

The terms and conditions for the reuse of this version of the manuscript are specified in the publishing policy. For all terms of use and more information see the publisher's website.

This item was downloaded from IRIS Università di Bologna (https://cris.unibo.it/)

When citing, please refer to the published version. 


\title{
Fluorescent Crystals and co-crystals of 1,8-naphthalimide derivatives: synthesis, structure determination and photophysical characterization
}

\author{
F. Grepioni, ${ }^{* a}$ S. d'Agostino, ${ }^{* a}$ D. Braga, ${ }^{a}$ A. Bertocco, ${ }^{a}$ L. Catalano, ${ }^{a}$ B. Ventura*b \\ A series of 4-pyperidinyl-1,8-naphtalimide derivatives containing at the N-position an $n$-methylpyridine $(n=2,3$, or 4$)$ have \\ been synthesized and isolated as crystalline materials. These isomers were further reacted, in the solid state, with the co- \\ former 1,4-diiodotetrafluorobenzene (I2F4) to give three new co-crystals of general formula $\mathbf{n}_{\mathbf{2}} \cdot \mathbf{1 2} \mathbf{F} \mathbf{4}$. All crystalline materials \\ have been thoroughly characterized in the solid state via single-crystal and powder X-ray diffraction, infrared spectroscopy \\ and thermal methods; in addition, the photophysical properties of all compounds have been investigated in solution and in \\ the solid state. The fluorescence features of the crystalline solids depend on the different arrangement of the molecules in \\ the lattice and co-crystallization leads to important changes in the emission properties of the crystalline compounds. \\ Emission quantum yields of the solids vary between 0.11 and 0.50 .
}

\section{Introduction}

Purely organic solid luminescent materials constitute an attractive field of research, ${ }^{1-9}$ not only from a theoretical point of view, but also because of their potential applications in optoelectronic devices. ${ }^{10-13}$ Recently, a turning point in this direction has come from crystal engineering, ${ }^{14-17}$ which aims to modify solid-state properties of materials by a careful control of the interactions "gluing" together the components into the resulting solid. So far, the most effective interactions are the hydrogen bond $(\mathrm{HB})^{18,19}$ and the halogen bond $(\mathrm{XB}) .^{20,21}$ The use of co-crystals as a means to modify optical properties such as fluorescence ${ }^{16,22-27}$ and phosphorescence ${ }^{28-33}$ of luminescent molecules is a strategy showing very promising results, whereas the systematic investigation of photophysical parameters, such as emission quantum yields and lifetimes, is still a less explored path.

This study deals with a series of isomers containing a 4piperidinyl-1,8-naphthalimide as the photoactive core, and at the $N$-position one of three different $n$-methylpyridines $(n=2$, 3 or 4 ; see Scheme 1). We have chosen the bulky and electron donating substituent piperidyl in order to: (i) ensure high fluorescence efficiency of the systems, and (ii) avoid a marked $\pi$-stacking in the solid state, usually responsible for self- quenching effects. ${ }^{34}, 35$ The former issue is based on the knowledge that 1,8-naphthalimide derivatives with an electrondonating group at the 4-position show intense fluorescence, arising from a charge-transfer excited state. ${ }^{36-39}$ This property has promoted their use mainly as components for electroluminescent devices ${ }^{40-42}$ and sensors. ${ }^{43-45}$ The substituted $\mathrm{n}$-methylpyridine has been introduced to promote formation of $\mathbf{n}_{\mathbf{2}} \cdot \mathbf{1 2} \mathbf{F} \mathbf{4}$ co-crystals via halogen bonds formation with the co-former 1,4-diiodotetrafluorobenzene (I2F4). The role of the co-former is twofold: it serves as a "solid diluent", thus further reducing self-quenching phenomena, and the presence of heavy atoms is expected to modulate the photophysical properties of the molecules in the co-crystals. ${ }^{28}$, 29

The different position of the pyridinic $\mathrm{N}$-atom plays a key role in directing the $12 \mathrm{~F} 4$ progressively closer to the naphthalenic core, and this is expected to lead to a modification of optical properties. The effect of the solid state molecular arrangement on the luminescence properties of all compounds is analyzed and discussed. Part of this work has been the subject of a recently deposited Italian patent. ${ }^{\ddagger}$

\section{Results and discussion}

\section{Synthesis and crystal growth}

The synthetic strategy employed for isomers 2-4 is based on two high yielding steps, namely (i) direct reaction between the 4-bromo-1,8naphthalic anhydride and piperidine in the high boiling solvent 2methoxyethanol, as reported in the literature, ${ }^{46,} 47$ followed by (ii) condensation with 2, 3 or 4-picolylamine in a mixture of water and ethanol in basic ambient (Scheme 1). 


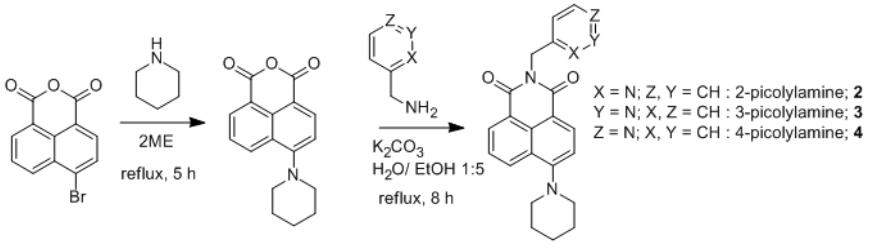

Scheme 1 Synthesis of 4-piperidinyl-1,8-naphthalic anhydride (1) and condensation reaction between 1 and $n$-picolylamines $(n=2,3$ or 4$)$ to give the $\mathbf{2}, \mathbf{3}$ and $\mathbf{4}$ isomers.

Single crystals suitable for X-ray diffraction were grown for all compounds via recrystallization from alcohols or dimethylformamide. ${ }^{\S}$ Co-crystals synthesis required more efforts. Direct co-crystallization from solution (solvents tested were ethanol, methanol, toluene, dimethylformamide, dichloromethane, chloroform/n-hexane) failed to produce pure products, necessary for the photophysical characterization, or products at all, as in most cases simple mixtures of starting materials were recovered. We tried to circumvent this problem by solid-state synthesis, but also manual grinding and kneading were not successful. Finally, quantitative reactions were obtained via grinding of the reagents as such in a ballmilling apparatus (see Experimental Section for operating conditions). Recrystallization via seeding yielded crystalline material suitable for single crystal characterization and photophysical measurements.

\section{Crystal structures}

Molecular structures, determined by single crystal X-ray diffraction analysis, for compounds 2-4 are shown in Fig. 1 . In all solids the naphthalimide moieties are almost exactly planar, and the piperidyl substituent shows the classic chair conformation; the main differences are found in the conformation of the $\mathrm{n}$-methylpyridinic substituent (see Fig. 1). In $\mathbf{2}$ and $\mathbf{3}$, in particular, the $\mathrm{N}$-atom points inward and outward with respect to the naphthalimide plane.

Crystal packings for 2, $\mathbf{3}$ and $\mathbf{4}$ are dominated by the quasi-planar naphthalimide moieties, which are responsible for the formation of two packing motifs, i.e. columnar stacking or herring-bone (see column A in Table 1).

(a)

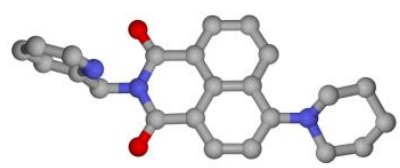

(b)

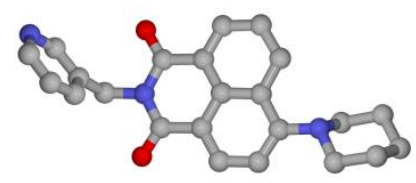

(c)

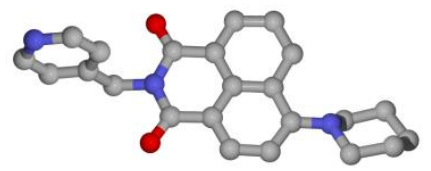

Fig. 1 The molecular structure of the isomers: (a) 2, (b) 3, (c) 4 . $\mathrm{H}_{\mathrm{CH}}$ atoms omitted for clarity.

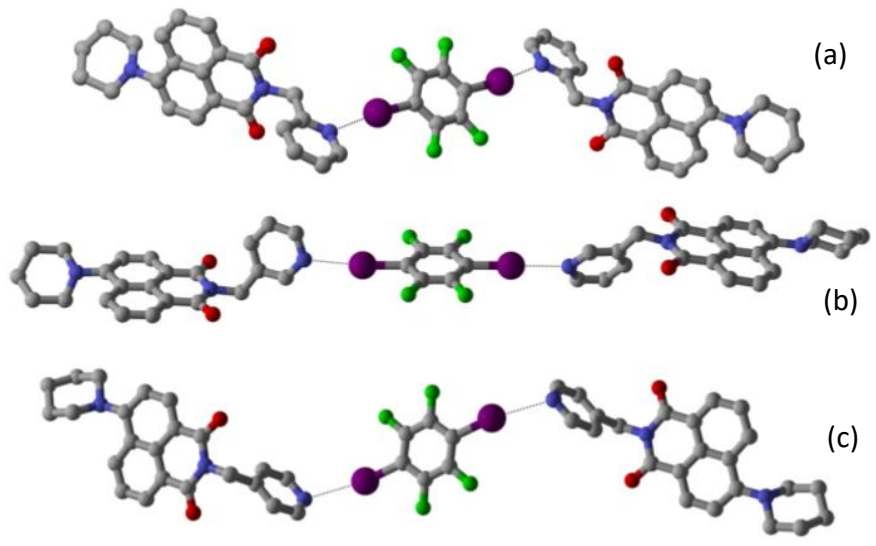

Fig. 2 Halogen bonds linking two naphthalimide derivatives and the I2F4 co-former in crystalline (a) $\mathbf{2}_{\mathbf{2}} \cdot \mathbf{1 2} \mathbf{F} \mathbf{4}$, (b) $\mathbf{3}_{\mathbf{2}} \cdot \mathbf{1 2} \mathbf{F} \mathbf{4}$, and (c) $\mathbf{4}_{\mathbf{2}} \cdot \mathbf{1 2} \mathbf{F} \mathbf{4}$. [Relevant XB parameters: $\mathbf{N} \cdot \boldsymbol{1}$ distance 2.908(6), 2.784(8)-2.789(8) and 2.997(3) $\AA$; N $\cdots \mid-C$ angle 171.9(2), 174.3(4)-174.9(3), $159.8(1)^{\circ}$ in $\mathbf{2}_{2} \cdot \mathbf{1 2 F 4}, \mathbf{3}_{2} \cdot \mathbf{1 2 F}$ and $\mathbf{4}_{2} \cdot 12 \mathrm{~F} 4$, respectively].

All co-crystalline materials are of general formula $\mathbf{n}_{\mathbf{2}} \cdot \mathbf{2} \mathbf{2 F} \mathbf{4}$, with the I2F4 co-former acting as a bridge between two $\mathrm{n}$ molecules via halogen bond, as is shown in Fig. 2.

The introduction of the 12F4 co-former strongly affects the packing in the $\mathbf{n}_{\mathbf{2}} \cdot \mathbf{1 2 F}$ series; however, the overall crystal packing is still dominated by the quasi-planar geometry of the naphthalimide units, with formation of $\pi$-stacking or herring-bone motifs (see column $B$ in Table 1), albeit the situation is now almost inverted.

Table 1 Comparison of naphthalimide cores arrangements in crystalline 2, 3 and 4 (column A) and corresponding co-crystals $\mathbf{2}_{2} \cdot 1 \mathbf{2} \mathbf{F} \mathbf{4}, \mathbf{3}_{2} \cdot \mathbf{2} \mathbf{F} \mathbf{4}$ and $\mathbf{4}_{2} \cdot \mathbf{1 2} \mathbf{F} \mathbf{4}$ (column B). For sake of clarity only the naphthalimide cores are shown, piperidyl substituents and $\mathrm{H}_{\mathrm{CH}}$ have been omitted.

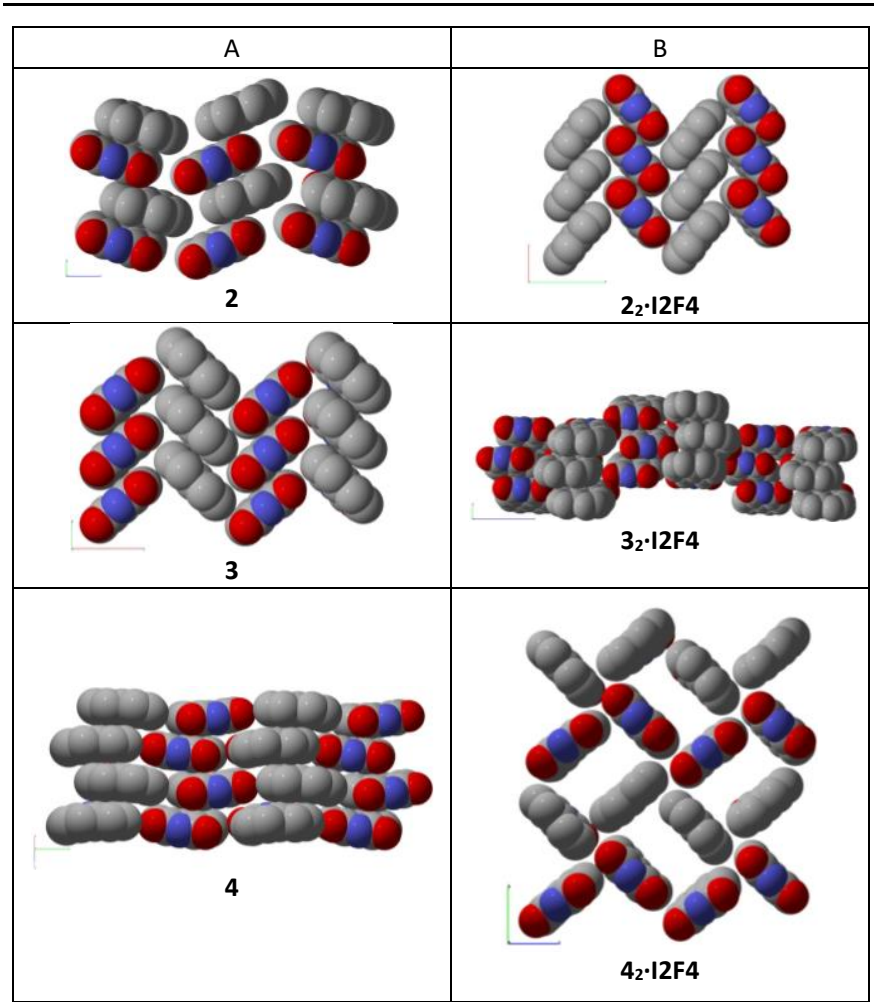


We have shown previously that the solid-state structures of naphthalimide systems are often dominated by extensive $\pi$ stacking interactions that may lead to marked changes in the optical properties due to exciton coupling. ${ }^{34}$ In this respect a closer structural analysis is necessary in order to evaluate the effect of the crystal packing on the optical features of crystalline 2-4 and $\mathbf{n}_{\mathbf{2}} \cdot \mathbf{1 2} \mathbf{F} \mathbf{4}$ co-crystals.

For each crystal and co-crystal one or more dimeric units are identified, formed by molecules that (i) are placed at short distance from each other, and (ii) interact via $\pi$-stacking or in herring-bone geometry, as shown in Scheme 2. All relevant parameters for dimers identification are indicated in the Scheme; the geometrical values for the actual dimers found in crystalline $\mathbf{2 - 4}$ and in co-crystals $\mathbf{n}_{\mathbf{2}} \cdot \mathbf{2} \mathbf{2 F} \mathbf{4}$ are reported in Fig. S2 and $\mathrm{S} 3$ in the ESI, respectively.

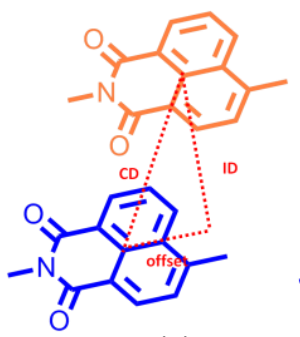

(a)

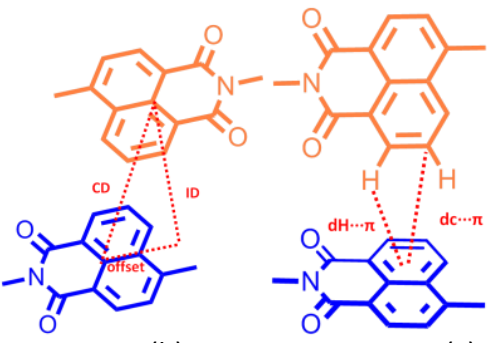

(b)
Scheme 2 Types of (a) head-to-head ( $\pi$-stacking), (b) head-to-tail ( $\pi$-stacking) and (c) edge-to-face (herring-bone) dimers, and geometrical parameters used to describe them: $C D=$ distance between the naphthalimide core centers, $I D=$ interplanar distance, and offset.

\section{Solid-state characterization}

The experimental and simulated X-ray powder diffraction patterns for compounds 2, $\mathbf{3}$ and $\mathbf{4}$ are shown in Fig. S4 in the ESI together with those of the corresponding co-crystals $\mathbf{2}_{2} \cdot \mathbf{1 2 F 4}, \mathbf{3}_{2} \cdot \mathbf{2} \mathbf{2 F} \mathbf{4}$, and $\mathbf{4}_{2} \cdot \mathbf{1 2 F 4}$. The effect of halogen bonds formation within the co-crystals was investigated also by FTIR spectroscopy. Infrared spectra for the series of isomers 2, $\mathbf{3}$ and $\mathbf{4}$ and the pure co-former 12F4 were collected and compared with those of the co-crystals $\mathbf{2}_{2} \cdot \mathbf{1 2} \mathbf{F 4}, \mathbf{3}_{2} \cdot \mathbf{1 2} \mathbf{F 4}$ and $\mathbf{4}_{2} \cdot \mathbf{2} \mathbf{2 F}$. In Fig. 3 we report the comparison for the components I2F4 and 2 and the co-crystal $2 \mathbf{2}_{2} \cdot \mathbf{2} \mathbf{F} \mathbf{4}$ (for other compounds and cocrystals see Fig. S5 and S6 in the ESI). According to the literature, halogen bond formation results in a small shift to lower frequencies for XB-donor diagnostical bands, and to higher frequencies for those of the XB-acceptor. ${ }^{48}$

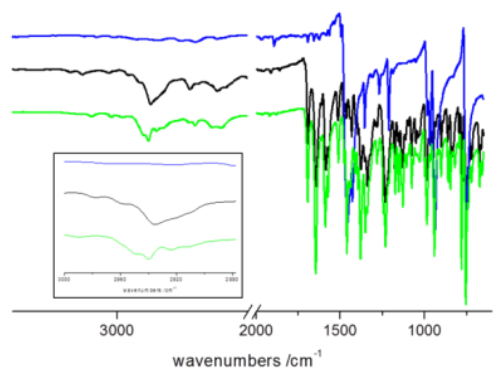

Fig. 3 ATR-FTIR spectra of components I2F4 (blue line), 2 (black line), and co-crystal $\mathbf{2}_{2} \cdot 12 \mathbf{F} 4$ (green line) in the range $3200-600 \mathrm{~cm}^{-1}$. The inset highlights the shift to higher frequencies for the $\mathrm{vC}_{\mathrm{pyr}}-\mathrm{H}$ stretching of the pyridine involved in halogen bond.
This effect is visible for the pyridine ring (the $\mathrm{XB}$-acceptor) involved in the halogen bond: the $\mathrm{vC}_{\mathrm{pyr}}-\mathrm{H}$ stretching (around $3000 \mathrm{~cm}^{-1}$ ) undergoes a shift from $2935 \mathrm{~cm}^{-1}$ to $2940 \mathrm{~cm}^{-1}$ on passing from 2 to $\mathbf{2}_{2} \cdot \mathbf{1 2 F}$. Analogous behavior is observed in $\mathbf{3}$ and $\mathbf{4}$, and in the $\mathbf{n}_{\mathbf{2}} \cdot \mathbf{1 2} \mathbf{F} \mathbf{4}$ co-crystals (see the ESI-Fig. S5 and S6).

The shift is less pronounced, or not even detected, for the halogen bond donor, because the iodine atom directly involved in the $\mathrm{XB}$ bond is bound to a carbon atom, and C-I vibrations lie in the IR region $<300 \mathrm{~cm}^{-1}$, which is beyond the measurement range of the instrument used $\left(400-4000 \mathrm{~cm}^{-1}\right) .49,50 \mathrm{In}$ the IR spectra of the XB donor indirect evidences of halogen bond formation (aromatic ring vibrations and $\mathrm{C}-\mathrm{F}$ stretching) are not in agreement with expected values (red shifts). These experimental results, however, are comparable with those reported in the literature. ${ }^{33}$

Thermal behavior of the compounds 2, $\mathbf{3}$ and $\mathbf{4}$ and of the co-crystals $\mathbf{2}_{2} \cdot \mathbf{2} \mathbf{2 F} \mathbf{4}_{\mathbf{3}} \mathbf{3}_{2} \cdot \mathbf{1 2} \mathbf{F} \mathbf{4}$, and $\mathbf{4}_{2} \cdot \mathbf{2} \mathbf{2 F} \mathbf{4}$ was investigated to determine their thermal stability (see Fig. S7-S10 in the ESI). Thermal gravimetric analysis (TGA) for all compounds indicates a weight loss of $c a$. 92$96 \%$ in the range $200-350^{\circ} \mathrm{C}$, corresponding to full degradation. TGA measurements for all co-crystals show a weight loss of $c a$. $35-36 \%$ in the range $100-230{ }^{\circ} \mathrm{C}$, followed by a weight loss of $c a .56-63 \%$ in the temperature range $240-400{ }^{\circ} \mathrm{C}$. In all cases the first loss is attributed to sublimation of the co-former I2F4, while the second, which occurs in the same temperature range as observed for pure compounds $\mathbf{2 -}$ 4 , is due to degradation of the naphthalimide derivatives.

\section{Photophysics}

The photophysical properties of compounds $\mathbf{2}, \mathbf{3}$ and $\mathbf{4}$ have been explored in five solvents of different polarity and viscosity, i.e. toluene (TOL), tetrahydrofuran (THF), dichloromethane (DCM), acetonitrile (ACN) and ethylene glycol (EtG). Absorption spectra and normalized emission spectra of the compounds in the different solvents are shown in Fig. 4 and Fig. S11 in the ESI. Absorption and emission data are summarized in Table 3 . Both absorption and emission spectra show a pronounced bathochromic shift with the increase of the polarity of the solvent, ascribed to the chargetransfer (CT) nature of the transition. ${ }^{51,52}$ The compounds are strongly fluorescent in TOL and DCM ( $\phi_{f 1}$ of the order of 0.80 ) whereas a drop in the emission quantum yield is observed in THF ( $\phi_{i 1}$ ca. 0.400.50 ) and a pronounced decrease is detected in ACN and EtG ( $\phi_{\mathrm{fl}} \mathrm{Ca}$. 0.04 and 0.01 , respectively). The florescence lifetime is analogously affected, with an important decrease in ACN and a further reduction in EtG (Table 3). It can be noted that whereas the radiative rate constants have little variation with the solvent, the non-radiative rate constants show a noticeable increase of about two orders of magnitude in ACN and EtG (Table 2). The decrease of fluorescence quantum yield of 4-amino-1,8-naphthalimides in polar and/or protic solvents due to an increased efficiency of non-radiative pathways is documented ${ }^{52-54}$ and ascribed either to a favored internal motion (nitrogen inversion of the amino group) ${ }^{54}$ or to a strong interaction with the solvent. ${ }^{53}$ The low emission quantum yields registered for $\mathbf{2}$, $\mathbf{3}$ and $\mathbf{4}$ in EtG, a viscous solvent with high coordination ability, corroborates the second explanation. 
Table 2 Absorption and fluorescence parameters (absorption maxima, molar absorption coefficients, emission maxima, fluorescence quantum yields, lifetimes, radiative and non-radiative rate constants) in the explored solvents at room temperature.

\begin{tabular}{|l|l|l|l|l|l|l|l|l|}
\hline & Solvent & $\lambda_{\text {abs }}^{\max } / \mathrm{nm}$ & $\varepsilon / \mathrm{M}^{-1} \mathrm{~cm}^{-1}$ & $\lambda_{f l}^{\max } / \mathrm{nm}^{\mathrm{a}}$ & $\phi \phi_{\mathrm{l}}^{\mathrm{b}}$ & $\tau / \mathrm{ns}^{\mathrm{b}}$ & $k_{\mathrm{r}} / \mathrm{s}^{-1}$ & $k_{\text {nr }} / \mathrm{s}^{-1}$ \\
\hline $\mathbf{2}$ & TOL & 399 & 9700 & 498 & 0.82 & 7.58 & $1.1 \times 10^{8}$ & $2.2 \times 10^{7}$ \\
& THF & 400 & 10200 & 519 & 0.41 & 6.74 & $6.1 \times 10^{7}$ & $8.7 \times 10^{7}$ \\
& DCM & 412 & 10500 & 525 & 0.81 & 9.18 & $8.8 \times 10^{7}$ & $2.1 \times 10^{7}$ \\
& ACN & 410 & 10300 & 540 & 0.041 & $0.66^{\mathrm{d}}$ & $6.2 \times 10^{7}$ & $1.4 \times 10^{9}$ \\
& EtG & 422 & 10200 & 550 & 0.011 & 0.18 & $6.1 \times 10^{7}$ & $5.5 \times 10^{9}$ \\
\hline $\mathbf{3}$ & TOL & 402 & 12800 & 502 & 0.82 & 7.80 & $1.1 \times 10^{8}$ & $1.8 \times 10^{7}$ \\
& THF & 405 & 13400 & 522 & 0.48 & 5.95 & $8.1 \times 10^{7}$ & $8.7 \times 10^{7}$ \\
& DCM & 414 & 13900 & 524 & 0.81 & 9.17 & $8.8 \times 10^{7}$ & $2.1 \times 10^{7}$ \\
& ACN & 410 & 13400 & 542 & 0.038 & $0.61^{\mathrm{d}}$ & $6.2 \times 10^{7}$ & $1.6 \times 10^{9}$ \\
& EtG & 424 & 13200 & 548 & 0.016 & 0.16 & $1.0 \times 10^{8}$ & $6.2 \times 10^{9}$ \\
\hline $\mathbf{4}$ & TOL & 404 & 10800 & 500 & 0.81 & 8.03 & $1.0 \times 10^{8}$ & $2.5 \times 10^{7}$ \\
& THF & 405 & 11100 & 520 & 0.50 & 6.01 & $8.3 \times 10^{7}$ & $8.3 \times 10^{7}$ \\
& DCM & 415 & 11400 & 520 & 0.81 & 9.00 & $9.0 \times 10^{7}$ & $2.1 \times 10^{7}$ \\
& ACN & 411 & 11600 & 542 & 0.042 & $0.58^{\mathrm{d}}$ & $7.2 \times 10^{7}$ & $1.7 \times 10^{9}$ \\
& EtG & 424 & 11100 & 552 & 0.011 & 0.14 & $7.9 \times 10^{7}$ & $7.1 \times 10^{9}$ \\
\hline
\end{tabular}

$\operatorname{TOL}\left(\varepsilon=2.38, \eta=0.586 \times 10^{-3} \mathrm{~Pa} \mathrm{~s}\right)$, THF $\left(\varepsilon=7.58, \eta=0.575 \times 10^{-3} \mathrm{~Pa} \mathrm{~s}\right), \mathrm{DCM}\left(\varepsilon=8.93, \eta=0.449 \times 10^{-3} \mathrm{~Pa} \mathrm{~s}\right), \mathrm{ACN}\left(\varepsilon=35.94, \eta=0.345 \times 10^{-3} \mathrm{~Pa} \mathrm{~s}\right), \mathrm{EtG}(\varepsilon=37.70$

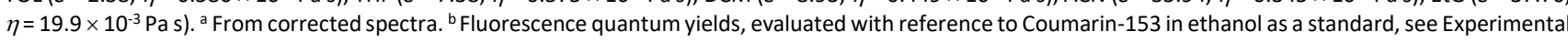

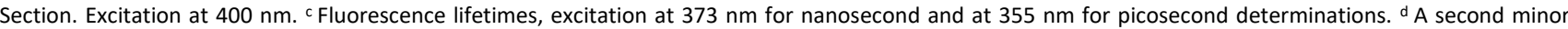
component (10-20\%) with lifetime of the order of 5-7 ns is detected.

Emission features registered at $77 \mathrm{~K}$ in toluene glassy matrix confirm a bright fluorescence peaking at around $490 \mathrm{~nm}$ for all the derivatives (Fig. S12 and Table S2 in the ESI), hypsochromically shifted with respect to room temperature as usually observed for CT transitions.

(a)

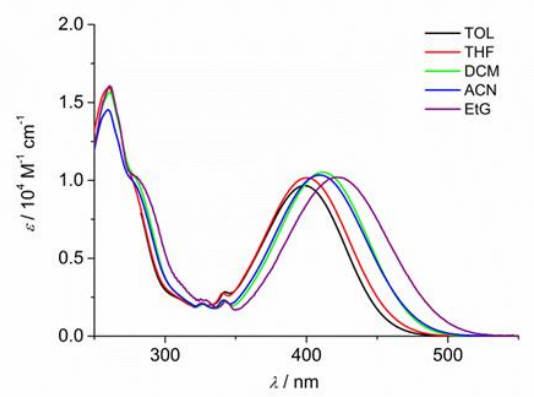

(b)

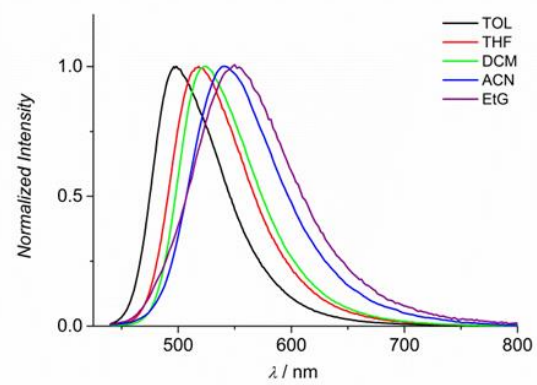

Fig. 4 (a) Absorption and (b) normalized emission spectra of $\mathbf{2}$ in the explored solvents at room temperature.

The luminescence properties of uncrushed powder samples of crystalline 2, 3, 4 and co-crystals $22_{2} \cdot 12 \mathrm{~F} 4, \mathbf{3}_{2} \cdot 12 \mathrm{~F} 4$, and $\mathbf{4}_{2} \cdot 12 \mathrm{~F} 4$ have been investigated. Normalized absorption and emission spectra of all the solid compounds are shown in Fig. 5 and photophysical parameters are summarized in Table 3. Unlike the solution case, where the three derivatives exhibit very similar absorption and emission features, crystals of 2, $\mathbf{3}$ and $\mathbf{4}$ show different optical properties, pointing out a dependence on the position of the pyridinic $\mathrm{N}$-atom with respect to the naphthalimide ring, i.e. on the crystal packing. Absorption and emission spectra progressively redshift in the order 4, 3, 2, with band maxima similar to those observed in solution in passing from TOL to DCM. Due to the high solvatochromism of these molecules, we can assume that the observed shifts are due to the local dielectric constant experienced by the molecule in the crystal, where the units are "solvated" by themselves in a geometry depending on the crystal arrangement. The fluorescence quantum yields are of the order of 0.30 for $\mathbf{3}$ and $\mathbf{4}$ and of 0.11 for $\mathbf{2}$ (Table 3). The lower value observed for $\mathbf{2}$ is likely due to the closer molecular packing of this crystal with respect to the other two cases $(C D=3.8 \AA$ for $\mathbf{2}$ and $5.3 \AA$ and $4.6 \AA$ for $\mathbf{3}$ and $\mathbf{4}$, respectively). These yields are significantly lower than those obtained in solutions in the less polar solvents but are still notable for organic molecules arranged in a crystal state.

Co-crystallization has a moderate effect on the absorption features of $\mathbf{2}$ and 3, whereas in case of $\mathbf{4}_{2} \cdot \mathbf{1 2 F} \mathbf{4}$ a red-shift of ca. $30 \mathrm{~nm}$ is observed in comparison to the pure crystal (Table 4). Fluorescence appears blue-shifted in $\mathbf{2}_{2} \cdot \mathbf{1 2} \mathbf{F} \mathbf{4}$ and $\mathbf{3}_{2} \cdot \mathbf{1 2} \mathbf{F} \mathbf{4}$ and red-shifted in $\mathbf{4}_{2} \cdot \mathbf{1 2} \mathbf{F} \mathbf{4}$ with respect to the corresponding crystals (Table 3 and Fig. 5). The behavior of $\mathbf{4}_{2} \cdot 12 \mathrm{~F} 4$ can be ascribed to the herring-bone arrangement of the units in the solid, markedly different from the $\pi$-stacked displacement of crystal 4 (Table 1). It is worthwhile to note that the main effect of co-crystallization is to affect the emission quantum yields of the solids. In fact, while the quantum yield of $\mathbf{2}_{\mathbf{2}} \cdot \mathbf{1 2} \mathbf{F} \mathbf{4}$ is very similar to that of $\mathbf{2}$, in the case of $\mathbf{3}$ and $\mathbf{4}$ the $\phi_{\mathrm{fl}}$ of the co-crystal is, 

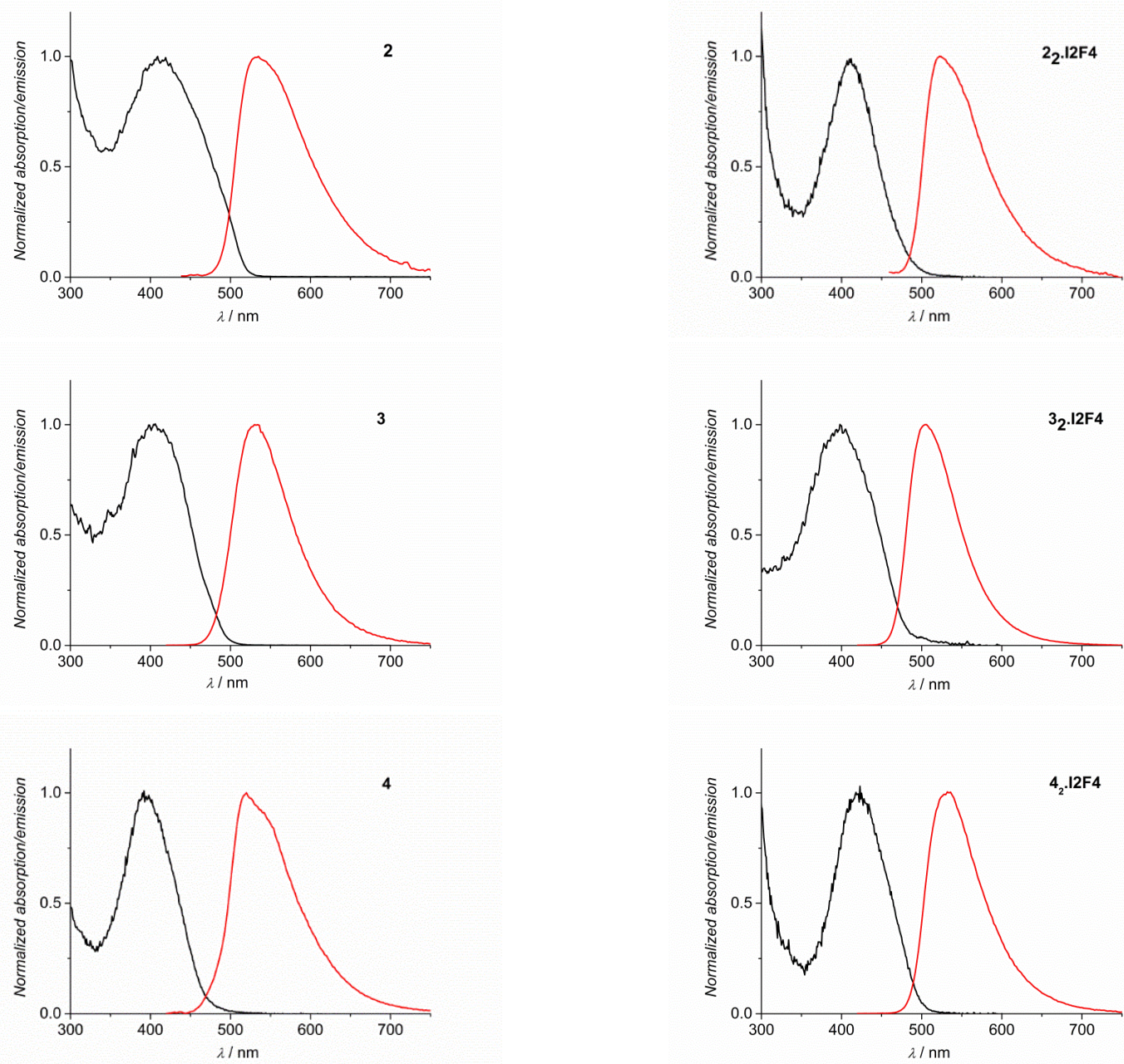

Fig. 5 Normalized absorption (black) and emission (red) spectra of crystals and co-crystals at room temperature.

respectively, twice and half that of the respective crystalline compound (Table 3 ). This outcome has to be ascribed to the different packing of the naphthalimide units in the co-crystals and the orientation of the heavy atom with respect to the naphthalimide core. Indeed, $\mathbf{3}_{2} \cdot \mathbf{1 2} \mathbf{F} \mathbf{4}$ shows the lowest packing index among all the examined solids and is the only co-crystal to possess voids in its structure (see Table $4 \mathrm{~b}$ ), allowing for a more "isolated" environment of the fluorophores, moreover the co-crystal formation has the effect of removing the disorder of the naphthalimide units formerly present in the parent crystal 3 . On the other hand, in $\mathbf{4}_{2} \cdot \mathbf{1 2} \mathbf{F} \mathbf{4}$ the naphthalimide units are surrounded by the halogenated co-formers (Table 1 and Figure 6), which could reduce their fluorescence efficiency by an external heavy atom effect. Overall, the fluorescence quantum yield of co-crystal $\mathbf{3}_{2} \cdot \mathbf{1 2 F} \mathbf{2}(0.50)$ is remarkable for a purely organic crystalline material.

Fluorescence decays of all the solid samples are multi-exponential, due to the diversity of local environments given by the inhomogeneous distribution of exciton traps such as structural defects, and have been treated both with a simplified bi-exponential fitting and with a distribution analysis of the decay components (Table 3). The values obtained with the latter analysis correlate well with the measured quantum yields and a lifetime of $8 \mathrm{~ns}$, similar to that measured for $\mathbf{3}$ in low polarity solvents, is observed for $\mathbf{3}_{2} \cdot \mathbf{2} \mathbf{2 F}$, confirming a close to monomeric arrangement experienced by the fluorophore in the co-crystal.

Table 3 Absorption and fluorescence parameters in the solid state at room temperature.

\begin{tabular}{|c|c|c|c|c|c|}
\hline & $\begin{array}{c}\lambda_{\text {abs }}^{\max } / \\
\mathrm{nm}\end{array}$ & $\begin{array}{c}\lambda_{f l}^{\max } / \\
\mathrm{nm}^{\mathrm{a}}\end{array}$ & $\phi_{\mathrm{fl}}^{\mathrm{b}}$ & $\tau / \mathrm{ns}^{\mathrm{c}, \mathrm{d}}$ & $\tau / \mathrm{ns}^{\mathrm{c}, \mathrm{e}}$ \\
\hline 2 & 413 & 534 & $0.110 \pm 0.012$ & $\begin{array}{l}1.8(44 \%) \\
5.8(56 \%)\end{array}$ & $3.2 \pm 2.4$ \\
\hline 3 & 404 & 532 & $0.264 \pm 0.050$ & $\begin{array}{l}3.4(29 \%) \\
8.3(71 \%)\end{array}$ & $6.2 \pm 3.5$ \\
\hline 4 & 393 & 520 & $0.334 \pm 0.019$ & $\begin{array}{l}2.5(38 \%) \\
8.1(62 \%)\end{array}$ & $5.0 \pm 3.5$ \\
\hline $22 \cdot 12 F 4$ & 410 & 522 & $0.176 \pm 0.009$ & $\begin{array}{c}1.6(45 \%) \\
5.1(55 \%)\end{array}$ & $2.8 \pm 2.1$ \\
\hline $3 \cdot 12 F 4$ & 399 & 506 & $0.503 \pm 0.040$ & $\begin{array}{l}4.4(11 \%) \\
8.7(89 \%)\end{array}$ & $8.0 \pm 2.5$ \\
\hline $42 \cdot 12 F 4$ & 421 & 534 & $0.143 \pm 0.008$ & $\begin{array}{l}1.3(64 \%) \\
4.1(36 \%)\end{array}$ & $1.7 \pm 1.4$ \\
\hline
\end{tabular}

a From corrected spectra, excitation at $400 \mathrm{~nm}$. ${ }^{\mathrm{b}}$ Absolute fluorescence quantum yields, excitation at $400 \mathrm{~nm}$. ' Luminescence lifetimes, excitation at $373 \mathrm{~nm}$. Values from bi-exponential fitting of the decays. ${ }^{~}$ Values from lifetime distribution analysis. 


\section{Experimental}

\section{Solution synthesis}

All solvents and chemicals were purchased from Sigma-Aldrich and used without further purification; distilled water was used.

Compounds 2, 3 and $\mathbf{4}$ were synthesized by condensation of 4piperidinyl-1,8-naphthalic anhydride (1) with the appropriate npicolylamine $(n=2,3$, or 4$)$, as shown in Scheme 1 . Compound 1 was obtained via modification of a previously reported procedure. ${ }^{46}$

Synthesis of 4-piperidinyl-1,8-naphthalic anhydride (1). A mixture of 4-bromo-1,8-naphthalic anhydride (277 $\mathrm{mg} ; 1.0 \mathrm{mmol})$, and piperidine ( $0.2 \mathrm{~mL} ; 2 \mathrm{mmol}$ ) in $3 \mathrm{~mL}$ of 2 -methoxyethanol (2ME) was heated and refluxed for $5 \mathrm{~h}$; the resulting solution was cooled to RT and distilled water was added until formation of a brownish precipitate was observed. The product was recovered by filtration and washed with cold $\mathrm{H}_{2} \mathrm{O}(5 \times 2 \mathrm{~mL})$.

Recrystallization from ethanol gave $220 \mathrm{mg}$ of 1 as orange needles. Yield $=78$ \%. M.p. $175-175^{\circ} \mathrm{C}$ (lit. $175-176^{\circ} \mathrm{C}$ ). ${ }^{47}$ ESI-MS (in MeOH): $\mathrm{m} / \mathrm{z}=282.2[\mathrm{M}+1]$.

Synthesis of 2, 3 and 4. Two equivalents of solid $\mathrm{K}_{2} \mathrm{CO}_{3}$ were added to a mixture of $1(540 \mathrm{mg}, 1.9 \mathrm{mmol})$ in $\mathrm{EtOH}(50 \mathrm{~mL})$. The mixture was stirred to complete dissolution (ca. $20 \mathrm{~min}$ ), then $0.24 \mathrm{~mL}(2.2$ mmol) of $n$-picolylamine were added. The solution was refluxed overnight, then it was cooled to $\mathrm{RT}$ and aqueous $\mathrm{K}_{2} \mathrm{CO}_{3}$ ( $\mathrm{pH}$ ca.11) was added dropwise until formation of a yellowish precipitate was observed. The product was recovered by filtration, washed with cold distilled water $(10 \times 2 \mathrm{~mL})$, purified via multiple recrystallization from EtOH / water (1: 1) and dried overnight in a desiccator. 2: Yield $=84 \%$; ESI-MS (in MeOH): $\mathrm{m} / \mathrm{z}=372.0\left[\mathrm{M}+\mathrm{H}^{+}\right] ;{ }^{1} \mathrm{H}-\mathrm{NMR}\left(\mathrm{CDCl}_{3}, 400 \mathrm{~Hz}\right): 8.6$ $(\mathrm{d}, J=7 \mathrm{~Hz}, 1 \mathrm{H}), 8.53(\mathrm{~m}, 3 \mathrm{H}), 8.4(\mathrm{~d}, J=8.2 \mathrm{~Hz}, 1 \mathrm{H}), 7.69(\mathrm{~m}, 2 \mathrm{H})$, $7.34(\mathrm{~d}, J=7.8 \mathrm{~Hz}, 1 \mathrm{H}), 7.2(\mathrm{~d}, J=8.2 \mathrm{~Hz}, 1 \mathrm{H}), 5.6(\mathrm{~s}, 2 \mathrm{H}), 3.2(\mathrm{~m}, 4 \mathrm{H})$, $1.9(\mathrm{~m}, 4 \mathrm{H}), 1.7(\mathrm{~m}, 2 \mathrm{H})$; m.p. $=189-191^{\circ} \mathrm{C} .3$ : Yield $=75 \%$; ESI-MS: $\mathrm{m} / \mathrm{z}=372.0[\mathrm{M}+\mathrm{H}+] ;{ }^{1} \mathrm{H}-\mathrm{NMR}\left(\mathrm{CDCl}_{3}, 400 \mathrm{~Hz}\right): 8.9(\mathrm{~s}, 1 \mathrm{H}), 8.65(\mathrm{~m}$, $2 \mathrm{H}), 8.5(\mathrm{~d}, J=7.8 \mathrm{~Hz}, 1 \mathrm{H}), 8.4(\mathrm{~d}, J=8.2 \mathrm{~Hz}, 1 \mathrm{H}), 7.87(\mathrm{~m}, 2 \mathrm{H}), 7.7$ $(\mathrm{t}, J=7.8 \mathrm{~Hz}, 1 \mathrm{H}), 7.2(\mathrm{~d}, J=8.2 \mathrm{~Hz}, 1 \mathrm{H}), 5.5(\mathrm{~s}, 2 \mathrm{H}), 3.3(\mathrm{~m}, 4 \mathrm{H}), 1.9$ $(\mathrm{m}, 4 \mathrm{H}), 1.7(\mathrm{~m}, 2 \mathrm{H}) ;$ m.p. $=156-157^{\circ} \mathrm{C}{ }^{\circ} \mathrm{C} .4$ : Yield $=86 \%$; ESI-MS: $\mathrm{m} / \mathrm{z}$ $=372.0\left[\mathrm{M}+\mathrm{H}^{+}\right] ;{ }^{1} \mathrm{H}-\mathrm{NMR}\left(\mathrm{CDCl}_{3}, 400 \mathrm{~Hz}\right): 8.6(\mathrm{~d}, J=7.4 \mathrm{~Hz}, 1 \mathrm{H}), 8.5$ (d, $J=5.9 \mathrm{~Hz}, 2 \mathrm{H}), 8.5(\mathrm{~d}, J=7.8 \mathrm{~Hz}, 1 \mathrm{H}), 8.4(\mathrm{~d}, J=8.2 \mathrm{~Hz}, 1 \mathrm{H}), 7.7$ $(\mathrm{t}, J=7.8 \mathrm{~Hz}, 1 \mathrm{H}), 7.5(\mathrm{~d}, J=5.9 \mathrm{~Hz}, 2 \mathrm{H}), 7.2(\mathrm{~d}, J=8.2 \mathrm{~Hz}, 1 \mathrm{H}), 5.4(\mathrm{~s}$, $2 \mathrm{H}, \mathrm{m}), 3.3(\mathrm{~m}, 4 \mathrm{H}), 1.9(\mathrm{~m}, 4 \mathrm{H}), 1.7(\mathrm{~m}, 2 \mathrm{H}) ; \mathrm{m} . \mathrm{p} .=179-180^{\circ} \mathrm{C}{ }^{\circ} \mathrm{C}$. ATR-FTIR spectra were recorded for all compounds (see $\mathrm{SI})$.

\section{Solid-state synthesis}

In the solid-state reactions 1,4-diiodotetrafluorobenzene (I2F4) and $\mathbf{2}$ or $\mathbf{3}$ or $\mathbf{4}$ were weighed in 1:2 molar ratio (to a total amount of ca. $200 \mathrm{mg}$ ) and ground together for 30-60 $\mathrm{min}$ in a ball-milling apparatus Retsch MM 20 operated at $20 \mathrm{~Hz}$. The solid products were divided in two portions: the first was directly analyzed via XRPD; the second was used to grow crystals suitable for SCXRD from a $\mathrm{MeOH}$ solution by the seeding technique. ${ }^{55}$ Prolonged grinding resulted in the amorphization of the products. Co-crystals formation was confirmed by comparison of the experimental XRPD patterns with those calculated on the basis of single crystal data. ATR-FTIR spectra were recorded for all co-crystals (see SI).

\section{Thermogravimetric analysis (TGA)}

Thermogravimetric analysis were performed with a Mettler Toledo Stare System. Heating was performed in a nitrogen flow $\left(20 \mathrm{~cm}^{3} \mathrm{~min}^{-}\right.$ 1) using a platinum crucible, at the rate of $5{ }^{\circ} \mathrm{C} \mathrm{min}-1$ up to decomposition. Sample weights were in the range $5-10 \mathrm{mg}$.

\section{Differential scanning calorimetry (DSC)}

Calorimetric measurements were performed with a Perkin-Elmer DSC-7 equipped with a PII intracooler. Temperature and enthalpy calibrations were performed using high-purity standards (n-decane, benzene and indium). Heating of the aluminium open pans containing the samples $\left(3-5 \mathrm{mg}\right.$ ) was carried out at $5^{\circ} \mathrm{C} \mathrm{min}^{-1}$ in the temperature range $40-350^{\circ} \mathrm{C}$.

\section{FTIR spectroscopy}

The attenuated total reflectance Fourier transform IR (ATR-FTIR) spectra were obtained using a Thermo Nicolet 6700 FT-IR spectrometer.

\section{NMR spectroscopy}

${ }^{1} \mathrm{H}$-NMR spectra were recorded on a Varian INOVA 400 (400 MHz) spectrometer and using chloroform-d bought from Sigma-Aldrich as solvent. Chemical shifts are reported in ppm using tetramethylsilane as the internal reference standard. Data are reported as follows: chemical shift, multiplicity $(\mathrm{s}=$ singlet, $\mathrm{d}=$ doublet, $\mathrm{t}=$ triplet, $\mathrm{m}=$ multiplet), coupling constants $(\mathrm{Hz})$, and number of protons $(\mathrm{nH})$.

\section{Crystal structure determination}

Single-crystal data for all compounds were collected at RT on an Oxford X'Calibur S CCD diffractometer equipped with a graphite monochromator (Mo-K $\alpha$ radiation, $\lambda=0.71073 \AA$ ). Data collection and refinement details are listed in Tables $4 \mathrm{a}$ and $4 \mathrm{~b}$. 
Table 4a Crystallographic data and details of measurements for crystalline 2, 3, 4 .

\begin{tabular}{|c|c|c|c|}
\hline & 2 & 3 & 4 \\
\hline Formula & $\mathrm{C}_{23} \mathrm{H}_{21} \mathrm{~N}_{3} \mathrm{O}_{2}$ & $\mathrm{C}_{23} \mathrm{H}_{21} \mathrm{~N}_{3} \mathrm{O}_{2}$ & $\mathrm{C}_{23} \mathrm{H}_{21} \mathrm{~N}_{3} \mathrm{O}_{2}$ \\
\hline fw & 371.43 & 371.43 & 371.43 \\
\hline Cryst. System & Monoclinic & Monoclinic & Monoclinic \\
\hline Space group & $\mathrm{P} 2{ }_{1} / \mathrm{c}$ & Pc & $\mathrm{P} 2{ }_{1} / \mathrm{a}$ \\
\hline Z & 4 & 2 & 4 \\
\hline a $(\AA)$ & $15.4693(8)$ & $12.432(1)$ & $7.4142(19)$ \\
\hline$b(\AA)$ & $7.1860(3)$ & $4.7462(5)$ & $16.069(4)$ \\
\hline c $(\AA ̊)$ & $17.5613(8)$ & $31.791(3)$ & $15.802(5)$ \\
\hline$\alpha$ (deg) & 90 & 90 & 90 \\
\hline$\beta$ (deg) & $111.307(5)$ & $100.259(9)$ & $93.08(3)$ \\
\hline$\gamma$ (deg) & 90 & 90 & 90 \\
\hline$V\left(\AA^{3}\right)$ & $1818.8(1)$ & $1845.8(3)$ & $1879.8(9)$ \\
\hline$D_{\text {calc }}\left(\mathrm{g} / \mathrm{cm}^{3}\right)$ & 1.356 & 1.337 & 1.312 \\
\hline packing coefficient $(\%)^{\mathrm{a}}$ & 70.2 & 69.1 & 67.9 \\
\hline accessible void $\left(\AA^{3}\right)^{b}$ & 0 & 0 & 0 \\
\hline$\mu\left(\mathrm{mm}^{-1}\right)$ & 0.088 & 0.087 & 0.085 \\
\hline Measd reflns & 14288 & 9064 & 8601 \\
\hline Indep reflns & 4340 & 5435 & 4343 \\
\hline $\mathrm{R}_{1}\left[\right.$ on $\left.\mathrm{F}_{0}^{2}, \mathrm{I}>2 \sigma(\mathrm{I})\right]$ & 0.0516 & 0.0640 & 0.1117 \\
\hline$w R_{2}$ (all data) & 0.1368 & 0.1782 & 0.1365 \\
\hline
\end{tabular}

a,b Calculated with Platon; for the accessible void calculation a probe of $1.2 \AA^{3}$ was employed.

The structure of compound $\mathbf{3}$ can be described in the monoclinic $\mathrm{P} 2_{1} / \mathrm{c}$ space group, but it is affected by heavy static disorder: for this reason solution and refinement were preferred in the lower symmetry space group Pc, which removes disorder and allows better characterization and description of the structural features.
Table $\mathbf{4 b}$ Crystallographic data and details of measurements for the co-crystals $\mathbf{2}_{\mathbf{2}} \cdot \mathbf{1 2} \mathbf{F} \mathbf{4}$ $3_{2} \cdot 12 \mathrm{~F} 4$ and $4_{2} \cdot 12 \mathrm{~F} 4$

\begin{tabular}{|c|c|c|c|}
\hline & $2 \cdot \cdot 12 \mathrm{~F} 4$ & $32 \cdot 12 \mathrm{~F} 4$ & $42 \cdot 12 F 4$ \\
\hline Formula & $\mathrm{C}_{52} \mathrm{H}_{42} \mathrm{~F}_{4} \mathrm{I}_{2} \mathrm{~N}_{6} \mathrm{O}_{4}$ & $\mathrm{C}_{52} \mathrm{H}_{42} \mathrm{~F}_{4} \mathrm{I}_{2} \mathrm{~N}_{6} \mathrm{O}_{4}$ & $\mathrm{C}_{52} \mathrm{H}_{42} \mathrm{~F}_{4} \mathrm{l}_{2} \mathrm{~N}_{6} \mathrm{O}_{4}$ \\
\hline fw & 1144.72 & 1144.72 & 1144.72 \\
\hline Cryst. System & Monoclinic & Monoclinic & Monoclinic \\
\hline Space group & $\mathrm{P} 2{ }_{1} / \mathrm{n}$ & $\mathrm{C} 2 / \mathrm{c}$ & $\mathrm{P} 2{ }_{1} / \mathrm{c}$ \\
\hline Z & 2 & 8 & 2 \\
\hline a $(\AA)$ & $5.1722(4)$ & $39.688(4)$ & $12.989(5)$ \\
\hline$b(\AA)$ & $11.517(1)$ & $7.4100(7)$ & $13.783(5)$ \\
\hline$c(\AA)$ & $38.904(3)$ & $31.521(3)$ & $12.664(5)$ \\
\hline$\alpha$ (deg) & 90 & 90 & 90 \\
\hline$\beta$ (deg) & $93.669(7)$ & $93.019(8)$ & $92.047(5)$ \\
\hline$\gamma$ (deg) & 90 & 90 & 90 \\
\hline$V\left(\AA^{3}\right)$ & $2312.7(3)$ & $9257.0(9)$ & $2265.9(2)$ \\
\hline$D_{\text {calc }}\left(\mathrm{g} / \mathrm{cm}^{3}\right)$ & 1.644 & 1.643 & 1.678 \\
\hline packing coefficient (\%) & 67.9 & 67.8 & 69.6 \\
\hline accessible void $\left(\AA^{3}\right)^{b}$ & 0 & 299.9 & 0 \\
\hline$\mu\left(\mathrm{mm}^{-1}\right)$ & 1.430 & 1.429 & 1.460 \\
\hline Measd refins & 25307 & 29886 & 10219 \\
\hline Indep reflns & 6047 & 9450 & 5206 \\
\hline $\mathrm{R}_{1}\left[\right.$ on $\left.\mathrm{F}_{0}^{2}, \mathrm{I}>2 \sigma(\mathrm{I})\right]$ & 0.0836 & 0.0882 & 0.0426 \\
\hline$w R_{2}$ (all data) & 0.1215 & 0.1534 & 0.0738 \\
\hline
\end{tabular}

a,b Calculated with Platon; for the accessible void calculation a probe of $1.2 \AA^{3}$ was employed.

All non-hydrogen atoms were refined anisotropically; $\mathrm{H}_{\mathrm{CH}}$ atoms for all compounds were added in calculated positions and refined riding on their respective carbon atoms. SHELX $97^{56}$ was used for structure solution and refinement on F2. The program PLATON ${ }^{57}$ was used to calculate intermolecular interactions. CYLview ${ }^{58}$ and Mercury ${ }^{59}$ were used for molecular graphics. These data can be obtained free of charge via www.ccdc.cam.ac.uk/conts/retrieving.htmL (or from the Cambridge Crystallographic Data Centre, 12 Union Road, Cambridge CB21EZ, UK; fax: (+44)1223-336-033; or e-mail: deposit@ccdc.cam.ac.uk). CCDC numbers are 1052879-1052885.

\section{Powder diffraction measurements}

$\mathrm{X}$-ray powder diffractograms in the $2 \theta$ range $5-40^{\circ}$ (step size, $0.02^{\circ}$; time/step, 20 s; 0.04 rad soller; $40 \mathrm{~mA} \times 40 \mathrm{kV}$ ) were collected on a Panalytical X'Pert PRO automated diffractometer equipped with an $\mathrm{X}^{\prime}$ Celerator detector and in Bragg-Brentano geometry, using $\mathrm{Cu} \mathrm{K} \alpha$ radiation without a monochromator. The program Mercury ${ }^{59}$ was used for simulation of X-ray powder patterns on the basis of single crystal data. Chemical and structural identity between bulk materials and single crystals was always verified by comparing experimental and simulated powder diffraction patterns. For variable temperature experiments the diffractometer was equipped with an Anton Paar TTK 450 system for measurements at controlled temperature. Data were collected in open air.

\section{Photophysics}


The solvents used were spectroscopic grade from C. Erba. Solid-state determination made use of powder samples placed inside two quartz slides.

Absorption spectra of solutions were recorded with a PerkinElmer Lambda 950 UV-Vis-NIR spectrophotometer. Reflectance spectra of solid samples were acquired with a Perkin-Elmer Lambda 9 UV/Vis/NIR spectrophotometer equipped with a $60 \mathrm{~mm}$ integrating sphere and converted in absorption spectra using the Kubelka-Munk function. ${ }^{60}$

Emission spectra were collected in right-angle mode for room temperature solutions and 77K frozen matrixes (quartz capillary tubes immersed in liquid nitrogen in a cold finger quartz dewar were used in the latter case) and in front-face mode for solids with a Edinburgh FLS920 fluorimeter equipped with Peltiercooled Hamamatsu R928 PMT (200-850 nm), and corrected for the wavelength dependent phototube response. Fluorescence quantum yields of samples $\left(\phi_{s}\right)$ in solution were evaluated with reference to Coumarin-153, in ethanol $(\phi=0.544),{ }^{61}$ by comparing areas under the corrected luminescence spectra by using the $r$ equation: $\phi_{s} / \phi=A_{r} n^{2}(\text { area })_{s} / A_{s} n^{2}{ }_{r}$ (area $)_{r}$, where $A$ is the absorbance, $n$ is the refractive index of the solvent employed and $s$ and $r$ stand for sample and reference, respectively. The concentration of the solutions was adjusted in order to have $A<$ 0.1 at the excitation wavelength. Absolute photoluminescence quantum yields of solid samples were measured on the same fluorimeter equipped with a 4 inches Labsphere integrating sphere, according to the method reported by Ishida et al. ${ }^{62}$ Each measurement was repeated from three to ten times. The limit of detection of the system is $2 \%$. The estimated errors are $2 \mathrm{~nm}$ on band maxima and $20 \%$ on quantum yields. Fluorescence lifetimes in the nanosecond range (TOL, THF, DCM and ACN solutions) were measured using an IBH 5000F Time Correlated Single Photon Counting apparatus with diode laser pulsed excitation source at 373 $\mathrm{nm}$. Fluorescence decays in the picosecond range (EtG solutions) were obtained with an apparatus based on a Nd:YAG laser (Continuum PY62-10) with a 35 ps pulse duration, $1.0 \mathrm{~mJ} /$ pulse, 355 $\mathrm{nm}$, and a Streak Camera (Hamamatsu C1587 equipped with M1952). The luminescence signals from 1000 laser shots were averaged and the time profile was measured in a wavelength range of ca. $30 \mathrm{~nm}$ around the emission maximum. The overall time resolution of the system after the deconvolution procedure is $10 \mathrm{ps} .{ }^{63}$

\section{Conclusions}

In this paper we have explored the possibility of modifying the solid-state photophysical properties of a series of 4pyperidinyl-1,8-naphtalimide derivatives containing at the $\mathrm{N}$ position an $n$-methylpyridine ( $\mathrm{n}=2,3$, or 4), via cocrystallization, conducted in the solid-state, with the co-former 1,4-diiodotetrafluorobenzene (I2F4). We have shown that (i) absorption and emission properties of all the derivatives in solution are highly solvent-dependent; (ii) solid-state fluorescence features depend on the crystal structure and the different arrangement of the molecules in the solid; (iii) important changes in the emission efficiency of the crystalline compounds can be induced upon co-crystallization. In particular, for co-crystals $\mathbf{3}_{2} \cdot 12 \mathrm{~F} 4$ and $\mathbf{4}_{2} \cdot 12 \mathrm{F4}$, a 2 -fold enhancement and a 2-fold decrease, respectively, of the fluorescence quantum yield in the solid state were observed with respect to the parent compounds $\mathbf{3}$ and $\mathbf{4}$. It is worthwhile to note that the high fluorescence quantum yield of co-crystal $\mathbf{3}_{2} \cdot 12 \mathrm{~F} 4(0.50)$ is unexpected for a crystalline compound containing halogenated units. This result evidences that a proper arrangement of the different units in the crystalline state can lead to predominance of rigidity and diluting effects over external heavy atom effects. The fluorescence efficiency of $\mathbf{3}_{2} \cdot \mathbf{1 2 F} \mathbf{4}$ makes it potentially useful for solid-state lighting and light-to-electricity conversion technologies. In particular, it could be suitable for use as a down-converter component in dye-sensitized and molecular solar cells to improve light harvesting and the photoelectric conversion efficiency of the cell. Investigations in this direction are currently in progress.

\section{Acknowledgements}

CNR (Project PM.P04.010 "MACOL"), MIUR project PRIN 2010CX2TLM, MIUR-CNR project Nanomax N-CHEM, and University of Bologna are gratefully acknowledged. Mr. Giorgio Longino (ISOF-CNR) is acknowledged for technical assistance.

\section{Notes and references}

‡ F. Grepioni, S. d'Agostino, D. Braga, A. Bertocco, L. Catalano and B. Ventura, "Co-cristalli con elevata resa di fluorescenza basati su derivati del 1,8-naftalimide e co-formeri alogenati“. 20/6/2014. Patent deposition number: RM2014A000327.

$\S$ Compounds 3 and $\mathbf{4}$ were obtained in two polymorphic modifications (see Fig. S1 in the ESI). In the case of $\mathbf{3}$ the second form was accidentally obtained as crystalline powder from a slurry in ethanol. In the case of $\mathbf{4}$ the first form was obtained only once as single crystals from a DMF solution, while the second formcrystallized from EtOH. After appearance of the second form, all attempts to crystallize again the first form were unsuccessful; this "disappearing polymorph" event is not a rarity, as it is discussed in the well-known and still much cited 1995 paper by Dunitz and Bernstein: (a) J. Bernstein and J. O. Henck, Disappearing and reappearing polymorphs - An anathema to crystal engineering? Mater. Res. Bull., 1998, 119-128; (b) J. D. Dunitz, and J. Bernstein, DISAPPEARING POLYMORPHS. Acc. Chem. Res. 1995, 28, 193-200.

1 S. P. Anthony, ChemPlusChem, 2012, 77, 518-531.

2 A. J. Jimenez, M.-J. Lin, C. Burschka, J. Becker, V. Settels, B. Engels and F. Wuerthner, Chem Sci., 2014, 5, 608-619.

3 M. Shimizu and T. Hiyama, Chem.-Asian. J., 2010, 5, 15161531.

4 A. Wakamiya, K. Mori and S. Yamaguchi, Angew. Chem., Int. Ed., 2007, 46, 4273-4276.

5 M.-S. Yuan, D.-E. Wang, P. Xue, W. Wang, J.-C. Wang, Q. Tu, Z. Liu, Y. Liu, Y. Zhang and J. Wang, Chem. Mat., 2014, 26, 2467-2477.

6 Y. Abe, S. Karasawa and N. Koga, Chem.-Eur. J., 2012, 18, 15038-15048.

7 S. H. Chen, N. Chen, Y. L. Yan, T. F. Liu, Y. W. Yu, Y. J. Li, H. B. Liu, Y. S. Zhao and Y. L. Li, Chem. Commun., 2012, 48, 9011-9013. 

Elsegood and T. Yamato, Chem.-Asian. J., 2012, 7, 28542863.

T. Hinoue, Y. Shigenoi, M. Sugino, Y. Mizobe, I. Hisaki, M. Miyata and N. Tohnai, Chem.-Eur. J., 2012, 18, 4634-4643. R. H. Friend, R. W. Gymer, A. B. Holmes, J. H. Burroughes, R. N. Marks, C. Taliani, D. D. C. Bradley, D. A. Dos Santos, J. L. Bredas, M. Logdlund and W. R. Salaneck, Nature, 1999, 397, 121-128.

K. Kim, S. Y. Kim and J.-L. Lee, J. Mat. Chem. C, 2014, 2, 2144-2149.

Y. Wei, W.-J. Wang, Y.-T. Huang, B.-C. Wang, W.-H. Chen, S.-H. Wu and C.-H. He, J. Mat. Chem. C, 2014, 2, 1779-1782. J. Huang, Y. Jiang, J. Yang, R. Tang, N. Xie, Q. Li, H. S. Kwok, B. Z. Tang and Z. Li, J. Mat. Chem. C, 2014, 2, 2028-2036.

C. B. Aakeroy, N. R. Champness and C. Janiak, CrystEngComm, 2010, 12, 22-43.

D. Braga, F. Grepioni and A. G. Orpen, D. Braga, F. Grepioni and A. G. Orpen Ed, Kluwer Academic Publishers, Dordrecht, 1999.

Q. Feng, M. Wang, B. Dong, C. Xu, J. Zhao and H. Zhang, CrystEngComm, 2013, 15, 3623-3629.

J. D. Wuest, Nature Chem., 2012, 4, 74-75.

D. Braga and F. Grepioni, Acc. Chem. Res., 2000, 33, 601608.

P. Gilli and G. Gilli, P. A. Gale and J. W. Steed Ed, WILEYVCH, Weinheim, 2012, pp. 2829-2867.

P. Metrangolo, J. S. Murray, T. Pilati, P. Politzer, G. Resnati and G. Terraneo, Cryst. Growth Des., 2011, 11, 4238-4246. P. Politzer, J. S. Murray and T. Clark, Phys. Chem. Chem. Phys., 2010, 12, 7748-7757.

Q. Feng, M. Wang, B. Dong, J. He and C. Xu, Cryst. Growth Des., 2013, 13, 4418-4427.

G.-G. Hou, H.-J. Zhao, J.-F. Sun, D. Lin, X.-P. Dai, J.-T. Han and H. Zhao, CrystEngComm, 2013, 15, 577-585.

S. P. Anthony, S. Varughese and S. M. Draper, J. Phys. Org. Chem., 2010, 23, 1074-1079.

Y. Tanaka, H. Tabata, N. Tajima, R. Kuroda and Y. Imai, CrystEngComm, 2014, 16, 1741-1748.

D. Yan, A. Delori, G. O. Lloyd, T. Friscic, G. M. Day, W. Jones, J. Lu, M. Wei, D. G. Evans and X. Duan, Angew. Chem., Int. Ed., 2011, 50, 12483-12486.

D. P. Yan, A. Delori, G. O. Lloyd, B. Patel, T. Friscic, G. M. Day, D. K. Bucar, W. Jones, J. Lu, M. Wei, D. G. Evans and X. Duan, Crystengcomm, 2012, 14, 5121-5123.

B. Ventura, A. Bertocco, D. Braga, L. Catalano, S. d'Agostino, F. Grepioni and P. Taddei, J. Phys. Chem. C, 2014, 118, 18646-18658.

O. Bolton, K. Lee, H. J. Kim, K. Y. Lin and J. Kim, Nat. Chem., 2011, 3, 205-210.

H. Y. Gao, X. R. Zhao, H. Wang, X. Pang and W. J. Jin, Cryst. Growth Des., 2012, 12, 4377-4387.

X. Pang, H. Wang, X. R. Zhao and W. J. Jin, CrystEngComm, 2013, 15, 2722-2730.

Q. J. Shen, X. Pang, X. R. Zhao, H. Y. Gao, H. L. Sun and W. J. Jin, CrystEngComm, 2012, 14, 5027-5034.

Q. J. Shen, H. Q. Wei, W. S. Zou, H. L. Sun and W. J. Jin, CrystEngComm, 2012, 14, 1010-1015.

S. d'Agostino, F. Grepioni, D. Braga, D. Moreschi, V. Fattori, F. Delchiaro, S. Di Mottaa and F. Negri, CrystEngComm, 2013, 15, 10470-10480.

F. C. Spano, Accounts Chem. Res., 2010, 43, 429-439.
M. S. Alexiou, V. Tychopoulos, S. Ghorbanian, J. H. P. Tyman, R. G. Brown and P. I. Brittain, J. Chem. Soc.-Perkin Trans. 2, 1990, 837-842.

P. Kucheryavy, G. F. Li, S. Vyas, C. Hadad and K. D. Glusac, J. Phys. Chem. A, 2009, 113, 6453-6461.

38 J. L. Magalhaes, R. V. Pereira, E. R. Triboni, P. Berci, M. H. Gehlen and F. C. Nart, J. Photochem. Photobiol. A-Chem., 2006, 183, 165-170.

39 V. Wintgens, P. Valat, J. Kossanyi, A. Demeter, L. Biczok and T. Berges, New J. Chem., 1996, 20, 1149-1158.

40 J. Liu, C. C. Min, Q. G. Zhou, Y. X. Cheng, L. X. Wang, D. G. Ma, X. B. Jing and F. S. Wang, Appl. Phys. Lett., 2006, 88, 083505.

41 J. Liu, G. L. Tu, Q. G. Zhou, Y. X. Cheng, Y. H. Geng, L. X. Wang, D. G. Ma, X. B. Jing and F. S. Wang, J. Mater. Chem., 2006, 16, 1431-1438.

42 Y. Wang, X. G. Zhang, B. Han, J. B. Peng, S. Y. Hou, Y. Huang, H. Q. Sun, M. G. Xie and Z. Y. Lu, Dyes Pigment., 2010, 86, 190-196.

43 R. M. Duke, E. B. Veale, F. M. Pfeffer, P. E. Kruger and T. Gunnlaugsson, Chem. Soc. Rev., 2010, 39, 3936-3953. K. Hanaoka, Y. Muramatsu, Y. Urano, T. Terai and T. Nagano, Chem.-Eur. J., 2010, 16, 568-572.

H. X. Wang, H. X. Wu, L. Xue, Y. Shi and X. Y. Li, Org. Biomol. Chem., 2011, 9, 5436-5444.

H. L. Dai, Y. Y. Yan, Y. Guo, L. L. Fan, Z. P. Che and H. Xu, Chem.-Eur. J., 2012, 18, 11188-11191.

47 A. T. Peters and M. J. Bide, Dyes Pigment., 1985, 6, 349375.

48 M. Baldrighi, G. Cavallo, M. R. Chierotti, R. Gobetto, P. Metrangolo, T. Pilati, G. Resnati and G. Terraneo, Mol. Pharm., 2013, 10, 1760-1772.

49 D. Hauchecorne, B. J. van der Veken, A. Moiana and W. A. Herrebout, Chem. Phys., 2010, 374, 30-36.

50 A. Mishra and A. D. E. Pullin, Aust. J. Chem., 1971, 24, 24932507.

51 S. Dhar, S. S. Roy, D. K. Rana, S. Bhattacharya, S. Bhattacharya and S. C. Bhattacharya, J. Phys. Chem. A, 2011, 115, 2216-2224.

52 Z. W. Li, Q. W. Yang, R. X. Chang, G. C. Ma, M. X. Chen and W. Q. Zhang, Dyes Pigment., 2011, 88, 307-314.

53 N. R. Deprez, K. A. McNitt, M. E. Petersen, R. G. Brown and D. E. Lewis, Tetrahedron Lett., 2005, 46, 2149-2153.

S. Saha and A. Samanta, J. Phys. Chem. A, 2002, 106, 47634771.

S. Khurshid, L. F. Haire and N. E. Chayen, J. Appl. Crystallogr., 2010, 43, 752-756.

56 Sheldrick, G. M. SHELX97, Program for Crystal Structure Determination; University of Göttingen: Göttingen, Germany, 1997.

Speck, A. L. PLATON; Acta Crystallogr., Sect. A, 1990, 46, C34.

Legault, C. Y. CYLview, Université de Sherbrooke, 2009.

59 C. F. Macrae, I. J. Bruno, J. A. Chisholm, P. R. Edgington, P. McCabe, E. Pidcock, L. Rodriguez-Monge, R. Taylor, J. van de Streek and P. A. Wood, J. Appl. Crystallogr., 2008, 41, 466-470.

60 F. C. Jentoft, in Advances in Catalysis, Vol 52, 2009, vol. 52, pp. 129-211.

K. Rurack and M. Spieles, Anal. Chem., 2011, 83, 12321242. 
H. Ishida, S. Tobita, Y. Hasegawa, R. Katoh and K. Nozaki, Coord. Chem. Rev., 2010, 254, 2449-2458.

63 L. Flamigni, A. M. Talarico, S. Serroni, F. Puntoriero, M. J. Gunter, M. R. Johnston and T. P. Jeynes, Chem.-Eur. J., 2003, 9, 2649-2659. 